\title{
Green synthesis of silk sericin-embedded silver nanoparticles and their antibacterial application against multidrug-resistant pathogens
}

Md. Abdullah Al Masud ${ }^{1}$, Hamid Shaikh², Md. Shamsul Alam', M. Minnatul Karim³, M. Abdul Momin", M. Ariful Islam ${ }^{1}$ and G. M. Arifuzzaman Khan ${ }^{1 *}$ (D)

\begin{abstract}
Background: The green synthesis strategy of metallic nanoparticles (NPs) has become popular due to being environmentally friendly. Stable silver nanoparticles (AgNPs) have been synthesized by natural products such as starch, soy protein, various extract of leaves, barks, and roots functioning both as reducing and stabilizing agents. Likewise, silk sericin (SS) is a globular protein discarded in the silk factory might be used for NP synthesis. In this research, we focus on the green synthesis and stabilization of AgNPs by SS as well as assessment of their antibacterial activities against some drug-resistant pathogen.

Results: SS was extracted from Bombyx mori silkworm cocoons in an aqueous medium. $17 \mathrm{w} / \mathrm{w} \%$ of dry sericin powder with respect to the cocoon's weight was obtained by freeze-drying. Furthermore, AgNPs conjugated to sericin, i.e., SS-capped silver nanoparticles (SS-AgNPs) were synthesized by easy, cost-effective, and environmentfriendly methods. The synthesized SS-AgNPs were characterized by UV-visible spectroscopy, Fourier-transform infrared-attenuated total reflection (FTIR-ATR) spectroscopy, transmission electron microscopy (TEM), and X-ray diffraction measurement. It has been found from the absorbance of UV-visible spectroscopy that a higher percent of SS-AgNPs was obtained at a higher concentration of silver nitrate solution. FTIR-ATR spectra showed that the carboxylate groups obtained from silk sericin act as a reducing agent for the synthesis of silver nanoparticles, while $\mathrm{NH}_{2}+$ and $\mathrm{COO}$ - act as a stabilizer of AgNPs. The X-ray diffractogram of SS-AgNPs was quite different from $\mathrm{AgNO}_{3}$ and sericin due to a change in the crystal structure. The diameter of AgNPs was around 20-70 nm observed using TEM. The synthesized SS-AgNPs exhibited strong antibacterial activity against multidrug-resistant pathogens, Escherichia coli and Pseudomonas aeruginosa. Minimal inhibitory/bactericidal concentrations against $E$. coli and $P$. aeruginosa were $20 \mu \mathrm{g} / \mathrm{mL}$.
\end{abstract}

Conclusions: This study encourages the use of Bombyx mori for the ecofriendly synthesis of SS-AgNPs to control multidrug-resistant microorganisms.

Keywords: Green synthesis, Silk sericin, SS-AgNPs, Antibacterial activity

\footnotetext{
*Correspondence: gm_arifuzzaman@yahoo.com; arifuzzaman@acce.iu.ac.bd

1 Department of Applied Chemistry and Chemical Engineering, Islamic

University, Kushtia 7003, Bangladesh

Full list of author information is available at the end of the article
}

\section{Springer Open}

(- The Author(s). 2021 Open Access This article is licensed under a Creative Commons Attribution 4.0 International License, which permits use, sharing, adaptation, distribution and reproduction in any medium or format, as long as you give appropriate credit to the original author(s) and the source, provide a link to the Creative Commons licence, and indicate if changes were made. The images or other third party material in this article are included in the article's Creative Commons licence, unless indicated otherwise in a credit line to the material. If material is not included in the article's Creative Commons licence and your intended use is not permitted by statutory regulation or exceeds the permitted use, you will need to obtain permission directly from the copyright holder. To view a copy of this licence, visit http://creativecommons.org/licenses/by/4.0/. 


\section{Background}

By-products contribute substantially towards industrial pollution. However, it is possible to turn by-products into valuable items by using appropriate management systems. Industrial pollution is not always from harmful, toxic ingredients, or heavy metals, but it can also result from ecofriendly products. For example, in the silk industry, water pollution occurs when wastewater from the degumming process runs out through drains. Worldwide, it is estimated that 400,000 tons of dry cocoons produce 50,000 tons of sericin each year. However, sericin is mostly discarded in silk processing wastewater and results in a high chemical oxygen demand (COD) and biological oxygen demand (BOD) levels in the degumming wastewater [1]. Therefore, the recovery and reuse of discarded sericin are beneficial because of its economic, social, and environmental advantages.

Silk sericin is a type of water-soluble globular protein derived from the silkworm Bombyx mori, and it represents a family of proteins whose molecular mass ranges from 10 to $310 \mathrm{kDa}$ [2-6]. Silk sericin has many unique properties, including biodegradability, nontoxicity, oxidation resistance, antimicrobial activity, ultraviolet (UV) resistance, and moisture absorption [1, 2, 7]. The physico-chemical properties of molecules are responsible for numerous applications in biomedicine and are influenced by the extraction method and silkworm lineage, which can lead to variations in the molecular weight and amino acid concentration of sericin. The silk sericin has been widely used in biomaterial applications due to its biocompatibility, biodegradability, and anti-oxidative and bioactive activities [8]. The presence of highly hydrophobic amino acids and their antioxidant potential makes it possible for sericin to be applied in the food and cosmetic industry. Silk sericin membranes are good bandage materials, and their film has adequate flexibility and tensile strength. Due to its substantial biocompatibility and infection-resistant nature, it is a novel wound coagulant material. Additionally, its flexibility and water absorption properties enable its use as a smooth cure for defects in the skin and do not cause any peeling of the skin under regeneration when detached from the skin [9]. Zhoarigetu et al. mentioned that sericin can be used as a raw material for making contact lenses: oxygen permeable membranes comprising fibroin and sericin with $10-16 \%$ water are used for making contact lenses and as artificial skin [1]. Masahiro et al. reported that the consumption of sericin enhances the bioavailability of $\mathrm{Zn}$, $\mathrm{Fe}, \mathrm{Mg}$, and $\mathrm{Ca}$ in rats and suggested that sericin is a valuable natural ingredient for the food industry [10]. Recently, sericin has been used as a reducing and stabilizing agent in the synthesis of metal nanoparticles [7]. The primary requirement for the synthesis of metal nanoparticles (NPs) is reducing the biological agents and other constituents present in the cells acting as stabilizing and capping agents, so there is no need to add capping and stabilizing agents from outside [11-15]. He et al. developed a novel, simple, one-step biosynthesis method to prepare a sericin-silver nanoparticle composite in situ in solution. Sericin served as the reductant of silver ion, the dispersant and stabilizer of the prepared sericin-silver nanoparticle composite [16]. Tahir et al. (2020) evaluated the antibacterial activity of sericinconjugated silver NPs synthesized using sericin as a reducing and capping agent [13, 17]. Aramwit et al. [8] synthesized silk sericin (SS)-capped silver nanoparticles (AgNPs) under alkaline conditions ( $\mathrm{pH}$ 11) using SS as a reducing and stabilizing agent instead of toxic chemicals. Most relevant studies stated that SS-capped AgNPs have substantial potential for use as antibacterials. For this reason, our interest has grown to extract SS from the cocoon of a very popular B. mori variety "Rajshahi Silk" and to introduce a green synthesis approach for the extraction of AgNPs in an aqueous neutral condition. The green synthesis of silver nanoparticles is primarily concerned with the selection of solvent medium, reducing agent, and nontoxic substances for stability $[18,19]$. In this context, it is essential to mention that the synthesis of silver nanoparticles using biological systems makes nanoparticles more biocompatible and environmentally benign.

AgNPs have strong antibacterial action towards grampositive, or gram-negative bacteria are reported in many past studies. Sondi and Salopek-Sondi first observed that AgNPs accumulate in the cellular membrane and form pits in the bacterial cell wall of Escherichia coli which led to an augmented permeability of the cell wall and ultimately the cell death [20]. Shrivastava et al. revealed that AgNPs create disorder in the integrity of the bacterial cell wall and membrane, supporting the permeability of the membrane and the leakage of the cell constituents, and eventually induce cell death [21]. Afterward, many advanced studies have been reported that DNA and protein of bacterial cell were destroyed by peroxidation, dephosphorylation, etc., reaction of $\mathrm{Ag}^{+}$ions in aerobic conditions [21-25]. Even then, some antibacterial mechanisms of AgNPs on multidrug-resistant bacteria remain unknowable. Nowadays, a group of pathogens namely ESKAPE (i.e., Enterococcus faecalis, Staphylococcus aureus, Klebsiella pneumoniae, Acinetobacter baumannii, Pseudomonas aeruginosa, and Enterobacter species) have become cause of several important nosocomial infections and already resistant to the last-line of antibiotics [26-29]. Yet again, Szmolka and Nagy were shown the multidrug resistivity of Escherichia coli in non-clinical sources [30]. In our study, we used Escherichia coli MZ20, Pseudomonas aeruginosa MZ2F, and Pseudomonas aeruginosa MZ4A. Previously, Zulkar et al. 
have reported that all bacteria are multidrug-resistant, e.g., Escherichia coli MZ20 is resistant to penicillin G $(\mathrm{P})$, tetracycline (TE), cotrimoxazole (COT), erythromycin (E), kanamycin (K), streptomycin (S), ciprofloxacin (CIP), ceftazidime (CAZ), nalidixic acid (NA), colistin (CL), ceftriaxone (CTR), doxycycline (DO), amoxicillin (AMX); Pseudomonas aeruginosa MZ2F is resistant to P-TE-COT-E-K-S-CAZ-NA-DO-AMX, and Pseudomonas aeruginosa MZ4A is resistant to P-TECOT-E-K-S-CAZ-NA-CL-DO-AMX [31].

In the present work, silver nanoparticles were synthesized using a simple, effective, and ecofriendly method using silk sericin. Silk sericin solution was extracted from B. mori silk cocoons and used as a reducing and stabilizing agent. The synthesized silver nanoparticles (AgNPs) were characterized using UV-visible spectroscopy, Fourier-transform infrared-attenuated total reflection (FTIR-ATR) spectroscopy, X-ray diffraction (XRD), and transmission electron microscopy (TEM). Additionally, we explored the antibacterial activity of biosynthesized silver nanoparticles (AgNPs) against multidrugresistant Escherichia coli MZ20, Pseudomonas aeruginosa MZ2F, and Pseudomonas aeruginosa MZ4A.

\section{Experimental}

\section{Materials}

Silk sericin is a protein that is extracted from silkworm cocoons. Silkworm cocoons were collected from the
Bangladesh Sericulture Research \& Training Institute, Rajshahi, 6207. Silver nitrate Anhydrous (extra pure) was brought from MOLYCHEM, India. All the analytical grade reagents used in this study were purchased from Merck, Germany.

Escherichia coli MZ20, Pseudomonas aerugiosa MZ2F, and Pseudomononas aeruginosa MZ4A were collected from the Department of Biotechnology and Genetic Engineering of our university. Bacterial strains were collected from different sources, such as hospital waste material and poultry litters. All bacterial strains were resistant to multiple drugs [31].

\section{Methods}

Extraction of silk sericin The silkworm cocoons were cut into small pieces and boiled at $90^{\circ} \mathrm{C}$ in demineralized water for $90 \mathrm{~min}$ at a ratio of 1 part cocoon to 40 parts water. Silk fibroin was separated using polyester filter cloths followed by Whatman filter paper. The SS solution was refluxed to remove volatile matters and concentrated until the desired concentration was achieved. The prepared SS colloidal solution $(60 \mathrm{ml}$ obtained from $5 \mathrm{~g}$ of cocoons) was frozen at $-20^{\circ} \mathrm{C}$ in a deep freeze (BIO Memory 175L) for about $12 \mathrm{~h}$. Then, the frozen SS was lyophilized in a freeze dryer (Yamato Freeze Dryer DC 401) for about $24 \mathrm{~h}$ until dry. Then, the percentage of the solid content of silk sericin was calculated and found

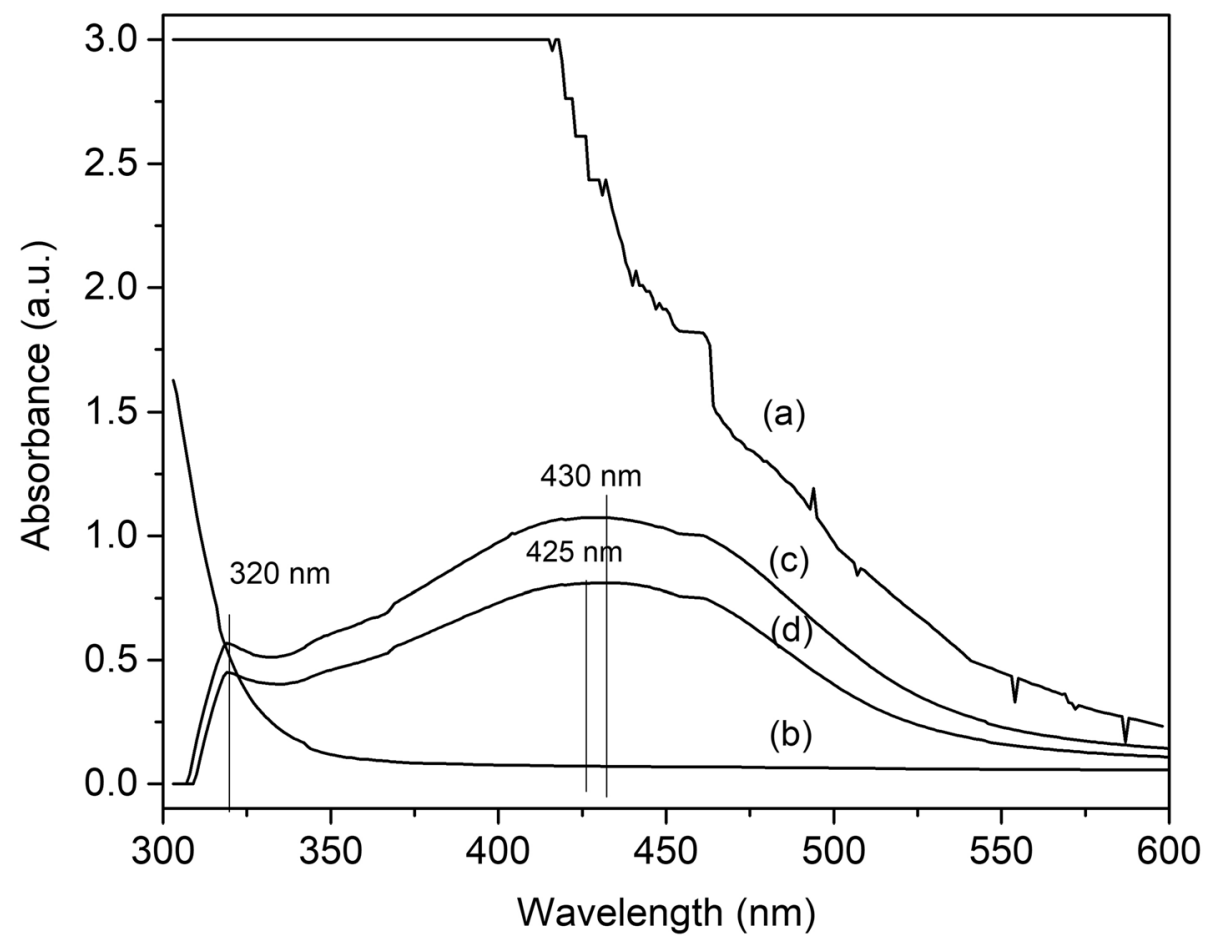

Fig. 1 UV-visible absorption peak of a silk sericin (SS), b $\mathrm{AgNO}_{3}, \mathbf{c}$ 1:6 SS-AgNPs, and $\mathbf{d}$ 1:8 SS-AgNPs 
to have an average value of $17 \mathrm{wt} \%$ sericin with respect to the weight of the silk cocoons.

Synthesis of silk sericin-capped silver nanoparticles Aqueous silver nitrate solution was prepared for AgNP synthesis. The lyophilized silk sericin was placed in a conical flask containing an aqueous $\mathrm{AgNO}_{3}$ solution. Two molar ratios of SS to $\mathrm{AgNO}_{3}$ were used: 1:6 and 1:8. The silver ions were reduced to silver nanoparticles (AgNPs) within a few minutes at $65^{\circ} \mathrm{C}$ with continuous stirring. The color of the solution changed from yellow to brown. The SS-AgNPs synthesized using different molar ratios were characterized using UV-visible spectroscopy, FTIRATR spectroscopy, XRD, and TEM measurements.

\section{Measurements}

UV-visible spectroscopy Sericin and SS-AgNPs were characterized using UV-1700 predominantly for accurate quantification of sericin protein and SS-AgNPs. The instrument can automatically calculate sample concentrations based on a standard curve using the $\mathrm{K}$ factor method.

Fourier-transform infrared-attenuated total reflection spectroscopy FTIR (ATR) spectra of the sericin and SSAgNPs were measured using an FTIR-ATR Instrument manufactured by SHIMADZU (IRAffinity-1S) with a resolution of $4 \mathrm{~cm}^{-1}$ in the wavenumber range 700 $4000 \mathrm{~cm}^{-1}$.

Transmission electron microscopy The size and shape of SS and SS-AgNPs were determined using TEM (model number is JEM-2100 F JEOL Japan) with ultrahigh regulation FETEM operating at $200 \mathrm{kV}$.

XRD measurement The crystalline behavior of SSAgNPs was examined using an X-ray diffractometer (Rigaku Ultima IV) operating at a voltage of $40 \mathrm{kV}$ and a current of $40 \mathrm{~mA}$ with $\mathrm{CuK \alpha}(\lambda=1.5406 \AA)$ radiation and a programmable divergent slit. The samples were scanned in the $2 \theta$ range $10^{\circ}-70^{\circ}$ with a scanning speed and step size of $3^{\circ} \mathrm{min}^{-1}$ and $0.02^{\circ}$, respectively.

Antimicrobial assessment The well diffusion method $[32,33]$ was used to test the antibacterial activities of synthesized silk sericin-silver nanoparticles (SS-AgNPs) according to the National Committee for Clinical Laboratory Standards (NCCLS) [34]. Three selected multidrug-resistant bacterial isolates (Escherichia coli MZ20, Pseudomonas aerugiosa MZ2F, Pseudomononas aeruginosa MZ4A were grown in Luria-Bertani (LB) for 18-20 h. The bacterial inoculums were prepared by maintaining a turbidity of $0.5 \mathrm{McFarland}$ standard (equal to $1.5 \times 10^{8}$ colony-forming units $\left.(\mathrm{CFU}) / \mathrm{ml}\right)$. Mueller

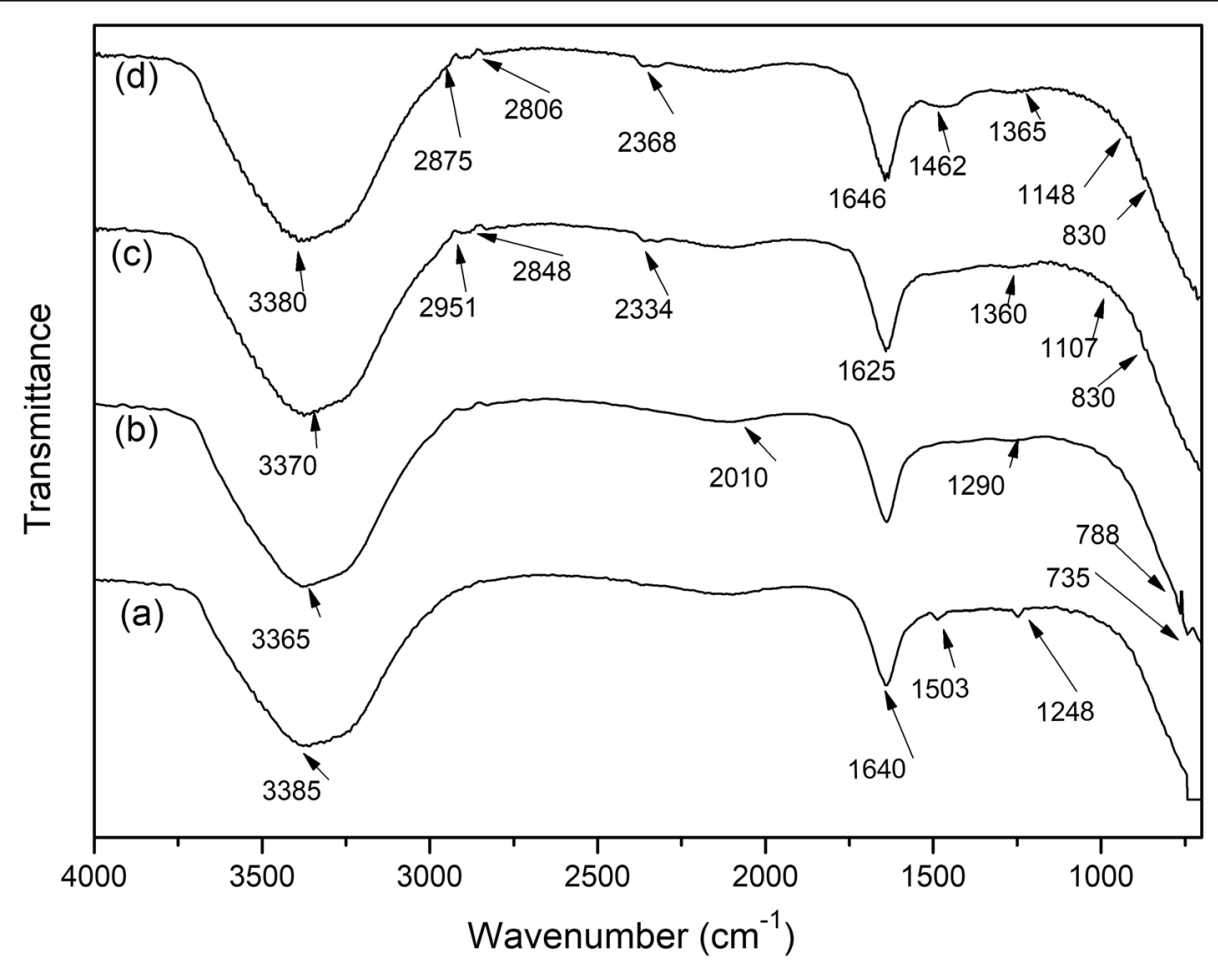

Fig. 2 Fourier-transform infrared-attenuated total reflection spectra of a silk sericin, b $\mathrm{AgNO}_{3}$ solution, c 1:6 SS-AgNPs, and d 1:8 SS- AgNPS 
Hinton agar (MHA) plates (150-mm diameter) were prepared, and bacterial suspensions were spread over the surface. The wells (9-mm diameter) were made using a cork borer in MHA plates. Each well was loaded with 70 $\mu \mathrm{l}$ of different concentrations $(10 \mu \mathrm{g} / \mathrm{ml}, 20 \mu \mathrm{g} / \mathrm{ml}, 30$ $\mu \mathrm{g} / \mathrm{ml}, 40 \mu \mathrm{g} / \mathrm{ml}$, and $50 \mu \mathrm{g} / \mathrm{ml}$ ) of SS-AgNPs. Plates were incubated at $37{ }^{\circ} \mathrm{C}$ for $24 \mathrm{~h}$. The diameters of the zones of inhibition around the wells were measured in millimeters $(\mathrm{mm})$. The experiment was performed in triplicate. Data were expressed as the mean \pm standard deviation.

\section{Results}

We developed a convenient method for the extraction of relatively pure sericin protein from $B$. mori silkworm cocoon. Maximum $17 \mathrm{w} / \mathrm{w} \%$ of yellow crude sericin powder was extracted after freeze-drying. The chemical composition viz. protein, sugar, ash, and amino acid of the isolated sericin powder have been identified by using the standard chemical test methods.
Table 1 Infrared band assignment of silk sericin (SS), $\mathrm{AgNO}_{3}$, and SS-Ag nanoparticles

\begin{tabular}{ll}
\hline $\begin{array}{l}\text { Infrared (IR) band } \\
\left(\mathbf{c m}^{-\mathbf{1}}\right)\end{array}$ & Band assignment \\
\hline $1700-1600$ & Amide I (C=O stretching vibration) \\
$1560-1500$ & $\begin{array}{l}\text { Amide II (N-H bending and C-N stretching } \\
\text { vibration) }\end{array}$ \\
$1300-1200$ & $\begin{array}{l}\text { Amide III (C-N-H in plane bending and C-N } \\
\text { stretching vibration) }\end{array}$ \\
$1107,1148,1360$, & $\begin{array}{l}\text { Free carboxylate groups (COO- stretching } \\
\text { vibration) }\end{array}$ \\
1462 & Amine N-H stretching vibration \\
$3365,3370,3380$, & Amine salt \\
830 &
\end{tabular}

\section{UV-visible spectroscopic analysis}

UV-visible spectroscopy is a common technique used to characterize the formation of AgNPs. In our investigation, AgNPs were formed from silver nitrate through the reducing action of sericin, which was confirmed by the UV-visible spectra shown in Fig. 1.
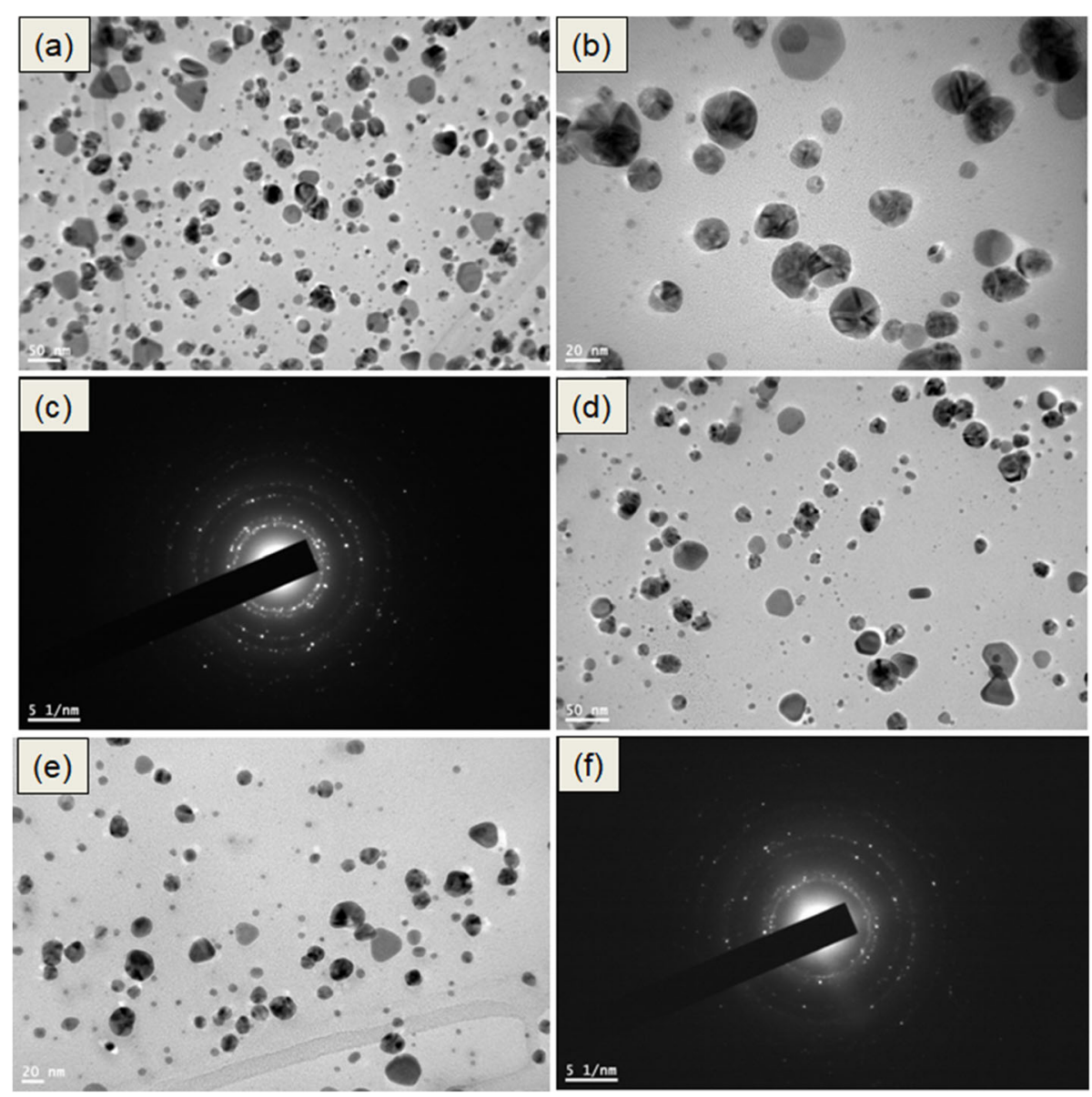

Fig. 3 Transmission electron microscopy images of synthesized silver nanoparticles-1:6 SS-AgNPs (a-c) and 1:8 SS-AgNPs (d-f) 


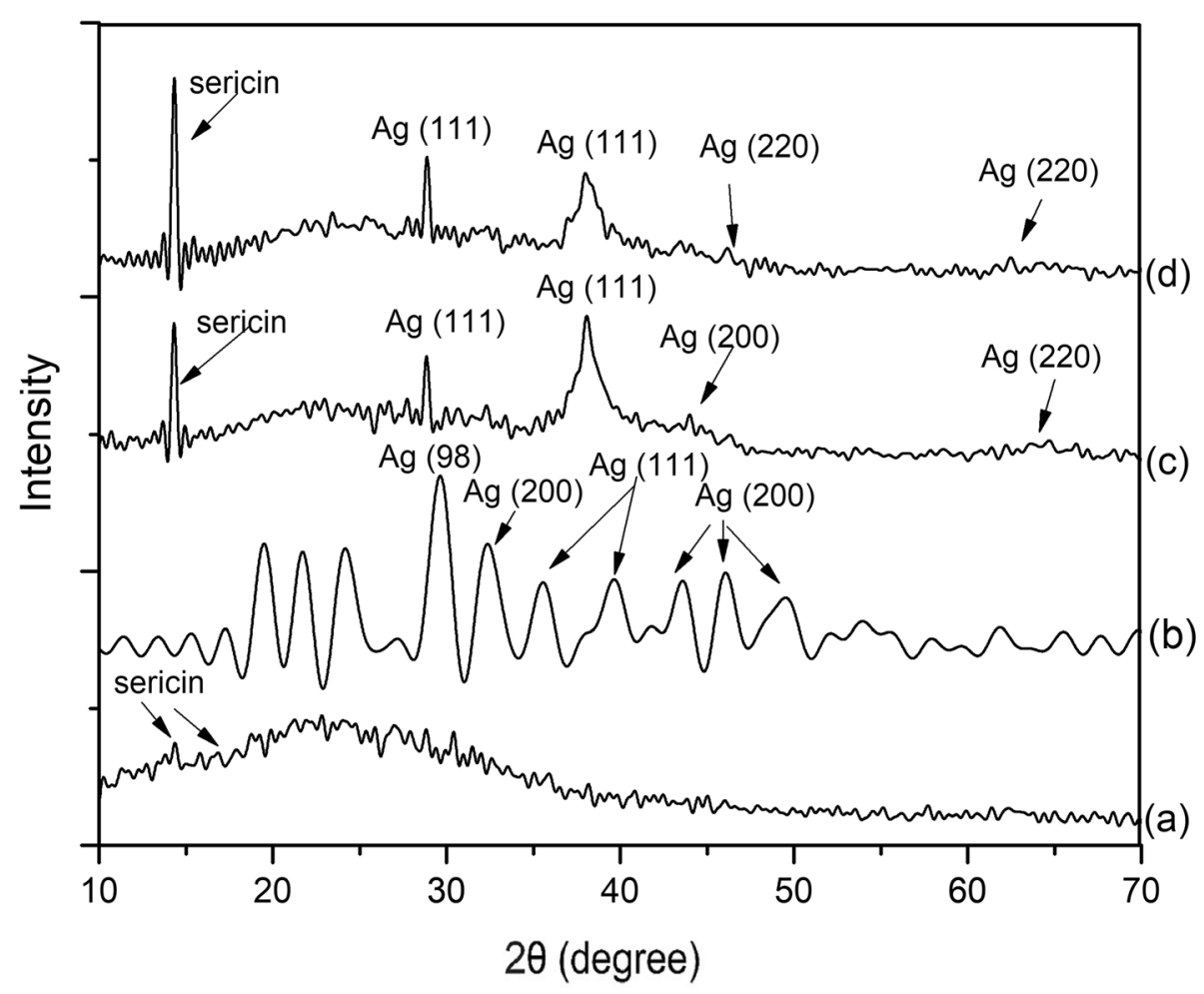

Fig. 4 X-ray diffraction diagram of a silk sericin, b $\mathrm{AgNO}_{3}$ solution, c 1:6 SS-AgNPs, and d 1:8 SS-AgNPS

The absorption peak at about $425 \mathrm{~nm}$ (absorbance $0.810 \%)$ indicated the formation of AgNPs. The UVvisible spectrum of SS-AgNPs of different SS to AgNP ratios showed a similar trend. The results exhibited a broad absorbance peak centered at around $430 \mathrm{~nm}$, which could be attributed to the surface plasmon resonance band of AgNPs [35]. In Fig. 1, the presence of AgNPs explained the observation of two surface plasmon resonance absorption bands at 320 and $430 \mathrm{~nm}$. According to the theoretical calculation of Kelly et al. [36], the multiplicity was caused by the quadruple plasmon resonances and in-plane dipole of Ag nanoplates, respectively [36-38]. Thus, a small shoulder peak was found at $320 \mathrm{~nm}$, implying the possible existence of different sizes and morphologies of AgNPs. The absorbance intensity of the 1:6 SS-AgNPs was higher than that of the 1:8 SS-AgNPs. The increasing silver fraction in the 1:8 SS-AgNPs could suggest that the silver ions were reduced continuously by sericin [16]. Another study mentioned that when the $\mathrm{AgNO}_{3}$ concentration was increased, tyrosine residues of sericin were gradually oxidized by silver ions, and reacting $\mathrm{AgNO}_{3}$ with $\mathrm{SS}$ to produce several AgNPs in solution was suggested [16].

\section{Fourier-transform infrared-attenuated total reflection spectroscopic analysis}

The structure of SS, $\mathrm{AgNO}_{3}$, and SS-AgNP samples was characterized using FTIR-ATR spectroscopy. Figure 2 shows the original spectra of SS, ${ }_{\mathrm{AgNO}}$, and SS-AgNPs at different ratios. The typical absorption bands in sericin protein, such as Amide I $\left(1700-1600 \mathrm{~cm}^{-1}\right)$, Amide II $\left(1560-1500 \mathrm{~cm}^{-1}\right)$, and Amide III $\left(1300-1200 \mathrm{~cm}^{-1}\right)$ were detected at 1640,1503 , and $1248 \mathrm{~cm}^{-1}$,

Table 2 X-ray diffraction scattering data for various crystalline structures

\begin{tabular}{lll}
\hline $\mathbf{2 \theta}$ & Plane & Structure \\
\hline $64.4,46.3$ & 220 & Face-centered cubic structure of metallic AgNPs \\
$32.3,44.3,48.8$ & 200 & Cubic phase of $\mathrm{Ag}_{2} \mathrm{O}$ crystal \\
$38.2,38.4,38.8$ & 111 & Face-centered cubic crystalline structure of metallic AgNPs \\
$27.9,28.2$ & 111 & Cubic phase of $\mathrm{Ag}_{2} \mathrm{O}$ crystal \\
29.5 & 98 & Pure silver crystal \\
$14.9,19.2$ & & Sericin crystalline and amorphous organic phase \\
\hline
\end{tabular}


respectively, which are illustrated in Table 1 . The absorption bands of $3 \mathrm{mM} \mathrm{AgNO} 3$ solution were detected at $735,788,1290$, and $2010 \mathrm{~cm}^{-1}$ [39].

Absorption bands of the 1:6 SS-AgNPs showed new functional groups, including carboxylate (1107 and $\left.1360 \mathrm{~cm}^{-1}\right)$ and amine salt $\left(830 \mathrm{~cm}^{-1}\right)$ and the absorption bands of the 1:8 SS-AgNPs showed the same functional groups as the 1:6 SS-AgNPs, including carboxylate $\left(1148,1365\right.$, and $1462 \mathrm{~cm}^{-1}$ ) and amine salt $\left(830 \mathrm{~cm}^{-1}\right)$. The peak at $1248 \mathrm{~cm}^{-1}$ could be assigned to the phenolic group of sericin, and the disappearance of the peak $1248 \mathrm{~cm}^{-1}$ at SS-AgNPs was due to the oxidation of the carboxyl group peak, which was identified at 1360, 1365, and $1462 \mathrm{~cm}^{-1}$ in Fig. 2. The SS-AgNPs represented the peak of Amide $\mathrm{I}$ at 1625 and $1640 \mathrm{~cm}^{-1}$ and amine $\mathrm{N}-\mathrm{H}$ stretching vibration at $3365-3385 \mathrm{~cm}^{-1}$ at $1: 6$ and $1: 8$ ratios, respectively, and the formation of AgNPs did not significantly alter the structure of sericin [11].

\section{Transmission electron microscopy}

TEM was conducted to determine the size and shape of nanoparticles. Figure 3a-e shows the TEM image of the 1: 6 SS-AgNPs and 1:8 SS-AgNPs, respectively. It was observed from the images that the synthesized SS-AgNPs at both the 1:6 and 1:8 mole ratios dispersed well in the aqueous solution. Most of the synthesized SS-AgNPs were clearly observed in the size range of $5-25 \mathrm{~nm}$ in Fig. 3b, e. The average particle size of the 1:6 SS-AgNPs was 10-30 $\mathrm{nm}$ and that of the 1:8 SS-AgNPs was 5-20 nm. The high resolution of TEM images showed the lattice structure of AgNPs with a range of $0.25 \mathrm{~nm}$, which was indicated by the face-centered cubic crystalline structure of the metallic AgNP plane of cubic silver $[8,40]$.

\section{X-ray diffraction analysis}

Figure 4 shows the crystalline structure of $\mathrm{SS}, \mathrm{AgNO}_{3}$, and SS-AgNPs obtained using XRD (Fig. 4). The XRD spectrum of SS, $\mathrm{AgNO}_{3}$, and SS-AgNPs has shown the characteristic patterns of the different crystalline structures, which are summarized in Table 2 . The value of $2 \theta$ at $14.9^{\circ}$ and $19.2^{\circ}$ could be related to the crystalline and amorphous organic phase of SS. Silver nitrate showed a cubic phase of $\mathrm{Ag}_{2} \mathrm{O}$ crystal and a face-centered cubic crystalline structure of metallic Ag. It was detected at $29.5^{\circ}, 32.3^{\circ}, 44.3^{\circ}$, and $48.8^{\circ}$, which corresponds to the (98), (200), (200), and (200) plane of cubic silver and $38.4^{\circ}$ and $38.8^{\circ}$ indicated (111), (111), the face-centered cubic crystalline structure of metallic Ag.

Again, the X-ray diffractogram made evident that the AgNPs were formed by the reduction of $\mathrm{Ag}^{+}$ions to $\mathrm{Ag}^{0}$ by the SS extract. The characteristic diffraction peaks at scattering angles $(2 \theta)$ of about $38.2^{\circ}, 44.3^{\circ}$, and $64.4^{\circ}$, which were attributed to the (111), (200), and (220)

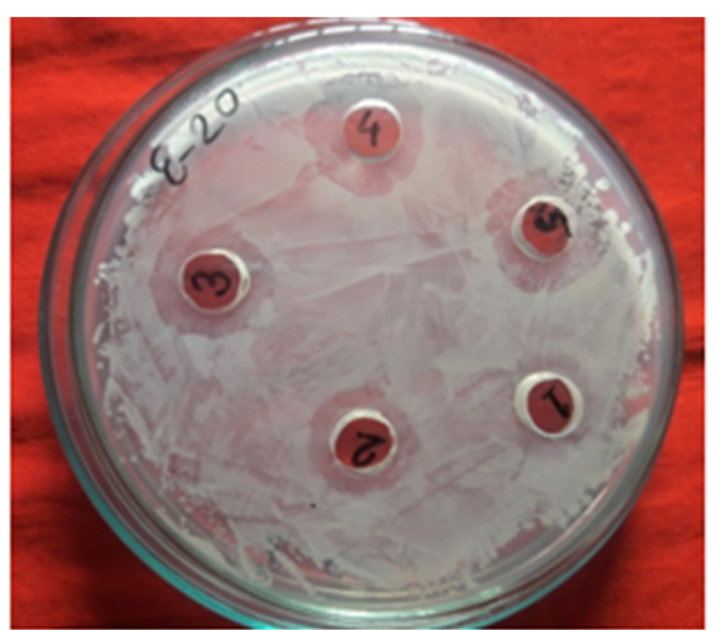

(a) Escherichia coli MZ20

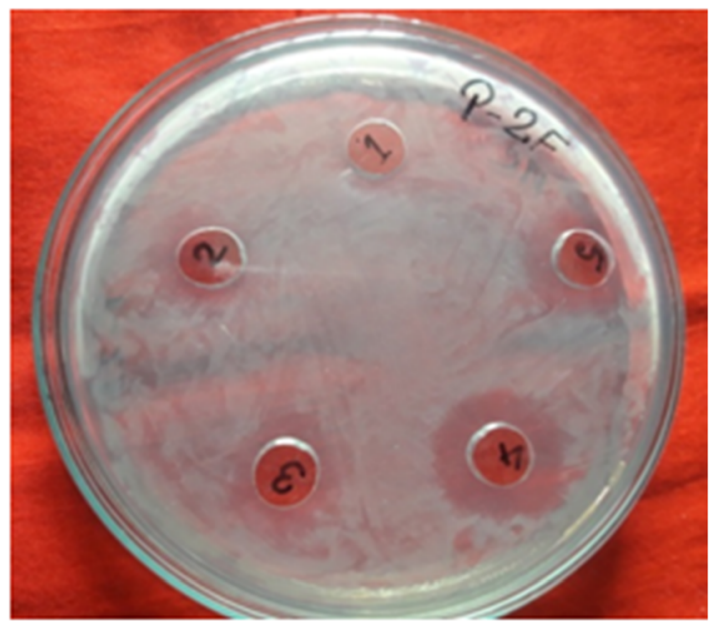

(b) Pseudomonas aeruginosa MZ2F

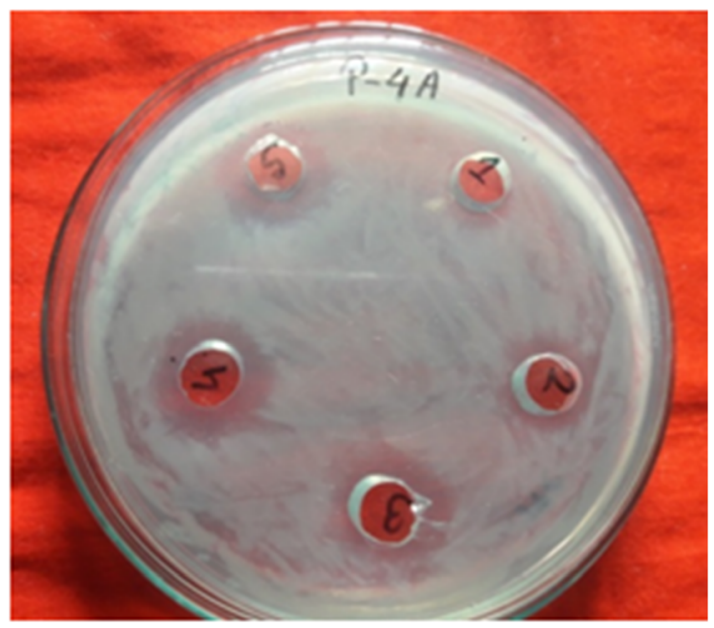

(c) Pseudomonas aeruginosa MZ4A

Fig. 5 Antibacterial activities of different concentrations of silk sericin-silver nanoparticles on multidrug-resistant Escerichia coli and Pseudomonas aeruginosa 
planes of the silver, respectively. Previous studies have also affirmed that the resultant particles are facecentered cubic structures of metallic AgNPs. The other peaks observed at $27.9^{\circ}, 32.3^{\circ}$, and $46.3^{\circ}$ were assigned to the (111), (200), and (220) planes of the cubic-phase $\mathrm{Ag}_{2} \mathrm{O}$ crystals in the sample [41]. This finding clearly indicates that the silver nanoparticles formed by the reduction of $\mathrm{Ag}^{+}$to $\mathrm{Ag}^{0}$ by the redox-active nature of tyrosine residues are crystalline in nature [42].

\section{Discussion}

The emergence of multidrug-resistant microorganisms is a serious concern for the medical sector, as it is difficult to control them with available antibiotics. So, it is essential to find out an alternative antimicrobial agent to control these multidrug-resistant microorganisms. Ecofriendly synthesized SS-AgNPs could be a potential candidate to control them. SS-AgNPs were synthesized and their antibacterial activity was investigated against drug-resistant pathogenic microorganisms, such as Pseudomonas aeruginosa and Escherichia coli. Tested pathogens (Pseudomonas aeruginosa and Escherichia coli) are resistant to different antibiotics reported [31]. The results show that eco-friendly synthesized SS-AgNPs have strong antibacterial efficacy against tested multidrug-resistant pathogens such as $E$. coli and $P$. aeruginosa (Fig. 5). Figure 5 reveals the inhibition zones around the well treated with SS-AgNPs. The antibacterial activity against pathogens was measured by calculating the diameter of the inhibition zone. The average results of the zone of inhibition are shown in Table 3. The MIC and MBC of SS-AgNPs against E. coli and P. aeruginosa were also determined. Figure 5 and Table 3 reveal that synthesized SS-AgNPs showed MIC of $20 \mu \mathrm{g} / \mathrm{mL}$ against both $E$. coli and $P$. aeruginosa. We compared the antibacterial activity of SS-AgNPs with SS and $3 \mathrm{mM}$ of $\mathrm{AgNO}_{3}$. The SS-AgNPs synthesized from 1:6 Silk sericin and $3 \mathrm{mM}$ of $\mathrm{AgNO}_{3}$ were selected for the study due to their high yield and stability. It has been proved that the cellular membrane of bacteria has a negative charge due to the presence of carboxyl, phosphate, and amino groups [43]. The positive charge confers electrostatic attraction between AgNPs and negatively charged cell membrane of the microorganisms, thereby facilitates AgNP attachment onto cell membranes [44]. It has also been reported that
AgNPs can anchor to the bacterial cell wall and consequently infiltrate it. This action will cause physical changes in the bacterial membrane, like the membrane damage, which can lead to cellular contents leakage and bacterial death $[45,46]$. Furthermore, the antibacterial mechanism of AgNPs is also due to their ability of producing high levels of reactive oxygen species (ROS) and free radical species which inhibited respiration and growth of cells [47, 48]. It is clearly observed in Fig. 6 that silk sericin did not have any activity against multidrug-resistant bacterial strains. However, $3 \mathrm{mM}$ of $\mathrm{AgNO}_{3}$ solution and SSAgNPs showed significant inhibition zones against tested drug-resistant $E$. coli and P. aeruginosa (Fig. 6 and Table 4). The results suggest that SS-AgNPs could be useful as an antimicrobial agent to control drug-resistant pathogens. The results of this study are consistent with previously reported studies $[49,50]$.

\section{Antimicrobial activity of synthesized SS-AgNPs}

\section{Conclusions}

The aim of this study was to recover SS from the wastewater of the silk degumming process, which causes water pollution by increasing BOD and COD. In this research, dry SS (17 w/w\% of cocoon) was recovered by freeze-drying without adding any reagent. Silver nanoparticles were synthesized and stabilized by extracted SS using a green synthesis technique. The SS-AgNPs were characterized using UV-visible spectroscopy, FTIR-ATR spectroscopy, TEM, and XRD measurement. The antibacterial activity of SS-AgNPs was examined. The results of the study are summarized briefly below:

- UV-visible spectroscopic absorbance showed a high percentage of SS-AgNPs was formed at a higher concentration of silver nitrate solution.

- The primary and secondary amide (Amide I, Amide II) absorption peak position of SS changed after the synthesis of SS-AgNPs.

- The remarkable crystalline structure of SS-AgNPs was shown in the X-ray diffractogram, which was different from that of the SS and silver nitrate crystalline structures.

- The sizes of SS-AgNPs were $\sim 20-120 \mathrm{~nm}$, which was observed by TEM.

Table 3 Antibacterial activity of synthesized silk sericin-capped silver nanoparticles (SS-AgNPs) against multidrug-resistant Escerichia coli and Pseudomonas aeruginosa

\begin{tabular}{llllll}
\hline Tested bacteria & \multicolumn{4}{l}{ Zone of inhibition $(\mathbf{m m})$} \\
\cline { 2 - 6 } & \multicolumn{1}{l}{ SS-AgNPs $(\boldsymbol{\mu g} / \mathbf{m l})$} & $\mathbf{3 0}$ & $\mathbf{4 0}$ & $\mathbf{5 0}$ \\
\cline { 2 - 6 } & $\mathbf{1 0}$ & $\mathbf{2 0}$ & $15 \pm 0.40$ & $17 \pm 0.38 \pm 0.34$ & $20 \pm 0.41$ \\
\hline Escherichia coli MZ20 & $\times$ & $16 \pm 0.18$ & $16.5 \pm 0.36$ & $19 \pm 0.20$ & $18.5 \pm 0.70$ \\
Pseudomonas aeruginosa MZ2F & $\times$ & $14.5 \pm 0.2$ & $17 \pm 0.18$ & $18 \pm 0.31$ & $18 \pm 0.40$ \\
\hline Pseudomonas aeruginosa MZ4A & $\times$ & &
\end{tabular}




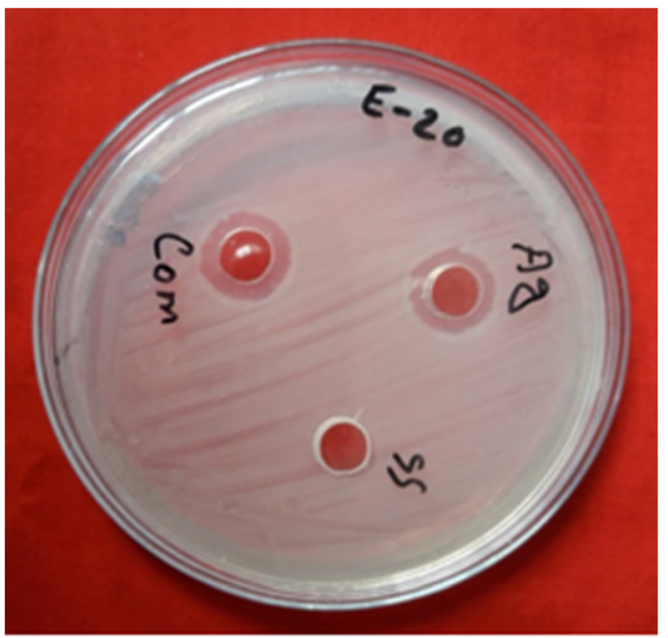

(a) Escherichia coli MZ20

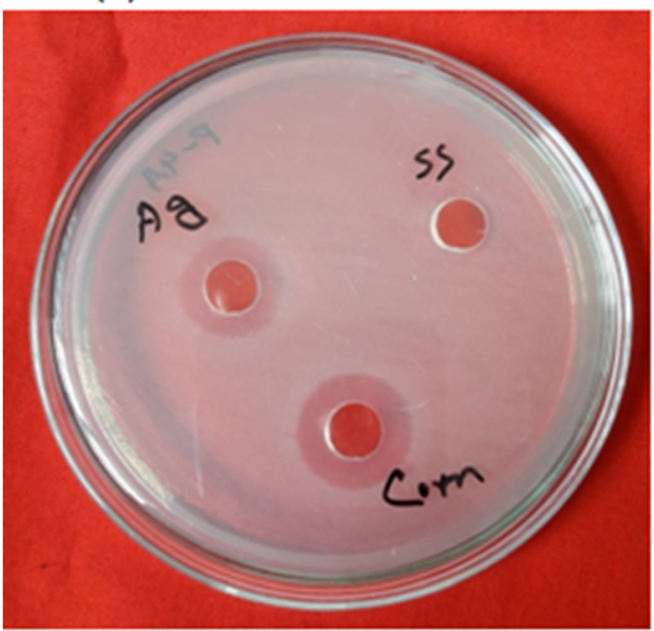

(b) Pseudomonas aeruginosa MZ2F

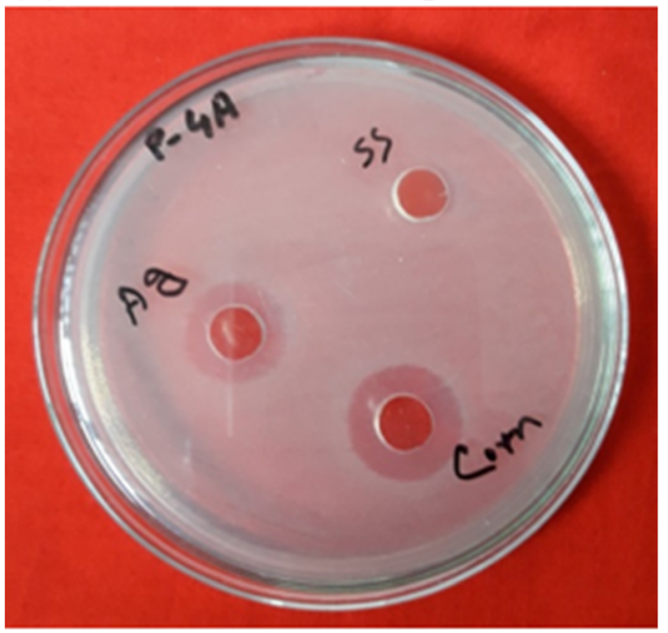

(c) Pseudomonas aeruginosa MZ4A

Fig. 6 Antibacterial activities of silk sericin (SS), $3 \mathrm{mM}$ of silver nitrate (Ag), and SS-AgNPs (Com) on multidrug-resistant Escerichia coli and Pseudomonas aeruginosa
Table 4 Antibacterial activity of silk sericin, $\mathrm{AgNO}_{3}$, and 1:6 SSAgNPs against multidrug-resistant Escerichia coli and Pseudomonas aeruginosa

\begin{tabular}{llll}
\hline Tested bacteria & \multicolumn{3}{l}{ Zone of inhibition $(\mathbf{m m})$} \\
\cline { 2 - 4 } & $\begin{array}{l}\text { Silk } \\
\text { Sericin } \\
\text { (SS) }\end{array}$ & $\begin{array}{l}\mathbf{3} \mathbf{~ m M ~ S i l v e r ~} \\
\text { nitrate }\end{array}$ & $\begin{array}{l}\mathbf{1 : 6 ~ S S - A g N P s ~ c o m - ~} \\
\text { posite } \mathbf{5 0} \mathbf{\mu g} / \mathbf{m l}\end{array}$ \\
& $\mathbf{5 0} \mathbf{~} \mathbf{g} / \mathbf{m l}$ & \\
\hline $\begin{array}{l}\text { Escherichia coli } \\
\text { MZ20 }\end{array}$ & $\times$ & $16 \pm 0.92$ & $20 \pm 0.41$ \\
$\begin{array}{l}\text { Pseudomonas } \\
\text { aeruginosa MZ2F }\end{array}$ & $\times$ & $17 \pm 0.43$ & $18.5 \pm 0.70$ \\
$\begin{array}{l}\text { Pseudomonas } \\
\text { aeruginosa MZ4A }\end{array}$ & $\times$ & $17 \pm 0.66$ & $18 \pm 0.40$ \\
\hline
\end{tabular}

- SS-AgNPs showed a substantial antibacterial effect against multidrug-resistant E. coli and Pseudomonas aeruginosa.

Therefore, it can be concluded that the green method of SS-AgNP synthesis is very simple, economical and ecofriendly and reduces the use of toxic and pollutioncausing reducing agents and stabilizers. Since the SSAgNPs have good antimicrobial properties, they could be used for biomedical purposes, especially in wound dressing. Future research should focus on the application of SS-AgNPs in membrane filters and hydrogels.

\section{Abbreviations}

BOD: Biological oxygen demand; COD: Chemical oxygen demand; FETE M: Field emission transmission electron microscopy; FTIR-ATR: Fouriertransform infrared-attenuated total reflection; LB: Luria-Bertani; NCCL S: National Committee for Clinical Laboratory Standards; SS: Silk sericin; SSAgNPs: SS-capped silver nanoparticles; TEM: Transmission electron microscopy; XRD: X-ray diffraction

\section{Acknowledgements}

We would like to thank the authority of Bangladesh Sericulture Research \& Training Institute, Rajshahi, Bangladesh, for providing the cocoon for this study.

\section{Authors' contributions}

GK conceived and designed the experiments. MAM and MI performed the experiment. MAM, MK, and HS wrote the manuscript. MAM, MM, MK, and GK analyzed the data. MA and GK reviewed and revised the manuscript and GK supervised and validated the data. The authors have read and approved the manuscript.

\section{Authors' information}

Md. Abdullah Al Masud and M. Ariful Islam are graduate students of the Department of Applied Chemistry and Chemical Engineering, Islamic University, Kushtia 7003, Bangladesh; Dr. Hamid Shaikh is an Assistant Professor of Department of Chemical Engineering, King Saud University, Saudi Arabia. He is a specialist on polymer characterization; Dr. Md. Shamsul Alam is a Professor of the Department of Applied Chemistry and Chemical Engineering, Islamic University, Kushtia 7003, Bangladesh. He specialized in polymer science and technology. Dr. Mohammad Minnatul Karim is a professor and Chairman of the Department of Biotechnology and Genetic Engineering, Islamic University, Kushtia 7003, Bangladesh. Dr. Md. Abdul Momin is a Professor and Chairman of the Department of Electric and Electronic Engineering, Islamic University, Kushtia 7003, Bangladesh. Dr. Gazi Md. Arifuzzaman Khan is a Professor of the Department of Applied Chemistry and Chemical Engineering, Islamic University, Kushtia 7003, Bangladesh. His 
area of specialization includes a biodegradable polymer and biocomposite materials.

\section{Funding}

This work was financially supported by the special allocation project (Financial Year 2018-2019, G. O. No.: 39.00.0000.009.14.006.19/EAS 17/440) of the Ministry of Science and Technology, Government of the People's Republic of Bangladesh.

\section{Availability of data and materials}

Not applicable.

\section{Declarations}

Ethics approval and consent to participate

Not applicable.

\section{Consent for publication}

Not applicable.

\section{Competing interests}

All authors do declare that there are no competing interests.

\section{Author details}

'Department of Applied Chemistry and Chemical Engineering, Islamic University, Kushtia 7003, Bangladesh. ²Department of Chemical Engineering, King Saud University, Riyadh, Saudi Arabia. ${ }^{3}$ Department of Biotechnology and Genetic Engineering, Islamic University, Kushtia 7003, Bangladesh. ${ }^{4}$ Department of Electric and Electronic Engineering, Islamic University, Kushtia 7003, Bangladesh.

Received: 20 January 2021 Accepted: 4 May 2021

Published online: 17 May 2021

\section{References}

1. Zhaorigetu S, Yanaka N, Sasaki M, Watanabe H, Kato N (2003) Inhibitory effects of silk protein, sericin on UVB-induced acute damage and tumor promotion by reducing oxidative stress in the skin of hairless mouse. J Photochem Photobiol B Biol 71(1-3):11-17. https://doi.org/10.1016/S1 011-1344(03)00092-7

2. Wu J-H, Wang Z, Xu S-Y (2007) Preparation and characterization of sericin powder extracted from silk industry wastewater. Food Chem 103(4):12551262. https://doi.org/10.1016/j.foodchem.2006.10.042

3. Freddi G, Mossotti R, Innocenti R (2003) Degumming of silk fabric with several proteases. J Biotechnol 106(1):101-112. https://doi.org/10.1016/j. jbiotec.2003.09.006

4. Altman GH, Diaz F, Jakuba C, Calabro T, Horan RL, Chen J, Lu H, Richmond J, Kaplan DL (2003) Silk-based biomaterials. Biomaterials 24(3):401-416. https://doi.org/10.1016/S0142-9612(02)00353-8

5. Padamwar MN, Pawar AP (2004) Silk sericin and its applications: a review. J Sci Ind Res (India) 63:323-329

6. Mondal M, Trivedy K, Kumar SN (2007) The silk proteins, sericin and fibroin in silkworm, Bombyx mori Linn., a review. Casp J Env Sci 5:63-76

7. Voegeli R, Meier J, Blust R (1993) Sericin silk protein: unique structure and properties. Cosmet Toilet 108:101-108

8. Aramwit P, Bang N, Ratanavaraporn J, Ekgasit S (2014) Green synthesis of silk sericin-capped silver nanoparticles and their potent anti-bacterial activity. Nanoscale Res Lett 9(1):1-7. https://doi.org/10.1186/1556-276X-9-79

9. Shelton EM, Johnson TB (1925) Researches on proteins. VII. The preparation of the protein "sericin" from silk. J Am Chem Soc 47(2):412-418. https://doi. org/10.1021/ja01679a020

10. Sasaki M, Yamada H, Kato N (2000) Consumption of silk protein, sericin elevates intestinal absorption of zinc, iron, magnesium and calcium in rats. Nutr Res 20(10):1505-1511. https://doi.org/10.1016/S0271-5317(00)80031-7

11. Prakasham RS, Kumar BS, Kumar YS, Shankar GG (2012) Characterization of silver nanoparticles synthesized by using marine isolate Streptomyces albidoflavus. J Microbiol Biotechnol 22(5):614-621. https://doi.org/10.4014/ jmb.1107.07013

12. Naveed UI Haq A, Nadhman A, Ullah I, Mustafa G, Yasinzai M, Khan I (2017) Synthesis approaches of zinc oxide nanoparticles: the dilemma of ecotoxicity. J Nanomater 2017:8510342. https://doi.org/10.1155/2017/851 0342-8510314

13. Irshad R, Tahir K, Li B, Ahmad A, R. Siddiqui A, Nazir S (2017) Antibacterial activity of biochemically capped iron oxide nanoparticles: a view towards green chemistry. J Photochem Photobiol B Biol 170:241-246. https://doi. org/10.1016/j.jphotobiol.2017.04.020

14. Ullah S, Ahmad A, Wang A, Raza M, Jan AU, Tahir K, Rahman AU, Qipeng Y (2017) Bio-fabrication of catalytic platinum nanoparticles and their in vitro efficacy against lungs cancer cells line (A549). J Photochem Photobiol B Biol 173:368-375. https://doi.org/10.1016/j.jphotobiol.2017.06.018

15. Hussain AA, Nazir S, Irshad R, Tahir K, Raza M, Khan ZUH, Khan AU (2021) Synthesis of functionalized mesoporous Ni-SBA-16 decorated with MgO nanoparticles for $\mathrm{Cr}(\mathrm{VI})$ adsorption and an effective catalyst for hydrodechlorination of chlorobenzene. Mater Res Bull 133:111059. https:// doi.org/10.1016/j.materresbull.2020.111059

16. He H, Tao G, Wang Y, Cai R, Guo P, Chen L, Zuo H, Zhao P, Xia Q (2017) In situ green synthesis and characterization of sericin-silver nanoparticle composite with effective antibacterial activity and good biocompatibility. Mater Sci Eng C 80:509-516. https://doi.org/10.1016/j.msec.2017.06.015

17. Tahir HM, Saleem F, Ali S et al (2020) Synthesis of sericin - conjugated silver nanoparticles and their potential antimicrobial activity. J Basic Microbiol 60(5):458-467. https://doi.org/10.1002/jobm.201900567

18. Raveendran P, Fu J, Wallen SL (2003) Completely "green" synthesis and stabilization of metal nanoparticles. J Am Chem Soc 125(46):13940-13941. https://doi.org/10.1021/ja029267j

19. Nahar K, Rahaman MH, Khan GMA et al (2021) Green synthesis of silver nanoparticles from citrus sinensis peel extract and its antibacterial potential. Asian J Green Chem 5:135-150. https://doi.org/10.22034/ajgc.2021.113966

20. Sondi I, Salopek-Sondi B (2004) Silver nanoparticles as antimicrobial agent: a case study on E. coli as a model for Gram-negative bacteria. J Colloid Interface Sci 275(1):177-182. https://doi.org/10.1016/j.jcis.2004.02.012

21. Shrivastava S, Bera T, Roy A, Singh G, Ramachandrarao P, Dash D (2007) Characterization of enhanced antibacterial effects of novel silver nanoparticles. Nanotechnology 18(22):18. https://doi.org/10.1088/0957-44 84/18/22/225103

22. Hamed S, Emara M, Shawky RM, el-domany RA, Youssef T (2017) Silver nanoparticles: antimicrobial activity, cytotoxicity, and synergism with $\mathrm{N}$ acetyl cysteine. J Basic Microbiol 57(8):659-668. https://doi.org/10.1002/ jobm.201700087

23. Dasgupta N, Ranjan S, Mishra D, Ramalingam C (2018) Thermal co-reduction engineered silver nanoparticles induce oxidative cell damage in human colon cancer cells through inhibition of reduced glutathione and induction of mitochondria-involved apoptosis. Chem Biol Interact 295:109-118. https://doi.org/10.1016/j.cbi.2018.07.028

24. Durán N, Marcato PD, De Conti R et al (2010) Potential use of silver nanoparticles on pathogenic bacteria, their toxicity and possible mechanisms of action. J Braz Chem Soc 21(6):949-959. https://doi.org/10.1 590/S0103-50532010000600002

25. Xiu ZM, Zhang QB, Puppala HL, Colvin VL, Alvarez PJJ (2012) Negligible particle-specific antibacterial activity of silver nanoparticles. Nano Lett 12(8): 4271-4275. https://doi.org/10.1021/nl301934w

26. Babapour E, Haddadi A, Mirnejad R, Angaji SA, Amirmozafari N (2016) Biofilm formation in clinical isolates of nosocomial Acinetobacter baumannii and its relationship with multidrug resistance. Asian Pac J Trop Biomed 6(6): 528-533. https://doi.org/10.1016/j.apjtb.2016.04.006

27. Taj Y, Essa F, Aziz F, Kazmi SU (2012) Study on biofilm-forming properties of clinical isolates of Staphylococcus aureus. J Infect Dev Ctries 6(05):403-409. https://doi.org/10.3855/jidc.1743

28. Valot B, Guyeux C, Rolland JY, Mazouzi K, Bertrand X, Hocquet D (2015) What it takes to be a Pseudomonas aeruginosa? The core genome of the opportunistic pathogen updated. PLoS One 10(5):1-15. https://doi.org/10.13 71/journal.pone.0126468

29. Subhan A, Irshad R, Nazir S, Tahir K, Ahmad A, Khan AU, Khan ZUH (2020) A new study of biomediated $\mathrm{Pd} /\{$ tiO\}2: a competitive system for Escherichia coli inhibition and radical stabilization. Mater Res Express 6(12):125430. https://doi.org/10.1088/2053-1591/ab5eaa

30. Szmolka A, Nagy B (2013) Multidrug resistant commensal Escherichia coli in animals and its impact for public health. Front Microbiol 4:1-13. https://doi. org/10.3389/fmicb.2013.00258

31. Nain Z, Islam MA, Minnatul Karim M (2019) Antibiotic resistance profiling and molecular phylogeny of biofilm forming bacteria from clinical and non- 
clinical environment in southern part of Bangladesh. Int J Enteric Pathog 7(2):37-43. https://doi.org/10.15171/ijep.2019.10

32. Magaldi S, Mata-Essayag S, Hartung De Capriles C et al (2004) Well diffusion for antifungal susceptibility testing. Int J Infect Dis 8(1):39-45. https://doi. org/10.1016/j.jij. 2003.03.002

33. Valgas C, De Souza SM, Smânia EFA, Smânia A (2007) Screening methods to determine antibacterial activity of natural products. Braz J Microbiol 38(2): 369-380. https://doi.org/10.1590/S1517-83822007000200034

34. National Committee for Clinical Laboratory Standards (1993) Performance standards for antimicrobial disk susceptibility tests, 5th edn. Approved Standard NCCLS Publication M2-A5, Villanova

35. Burda C, Chen X, Narayanan R, El-Sayed AM (2005) Chemistry and properties of nanocrystals of different shapes. Chem Rev 105(4):1025-1102. https://doi. org/10.1021/cr030063a

36. Kelly KL, Coronado E, Zhao LL, Schatz GC (2003) The optical properties of metal nanoparticles: the influence of size, shape, and dielectric environment. J Phys Chem B 107(3):668-677. https://doi.org/10.1021/jp026731y

37. Drury A, Chaure S, Kröll M, Nicolosi V, Chaure N, Blau WJ (2007) Fabrication and characterization of silver/polyaniline composite nanowires in porous anodic alumina. Chem Mater 19(17):4252-4258. https://doi.org/10.1021/ $\mathrm{cm} 071102 \mathrm{~s}$

38. Jin R, Cao Y, Mirkin CA, Kelly KL, Schatz GC, Zheng JG (2001) Photoinduced conversion of silver nanospheres to nanoprisms. Science (80- ) 294(5548): 1901-1903. https://doi.org/10.1126/science.1066541

39. Augustine R, Rajarathinam K (2012) Synthesis and characterization of silver nanoparticles and its immobilization on alginate coated sutures for the prevention of surgical wound infections and the in vitro release studies. Int J Nano Dimens 2:205-212. https://doi.org/10.7508/ijnd.2011.03.009

40. Zeng J, Zheng Y, Rycenga M, Tao J, Li ZY, Zhang Q, Zhu Y, Xia Y (2010) Controlling the shapes of silver nanocrystals with different capping agents. J Am Chem Soc 132(25):8552-8553. https://doi.org/10.1021/ja103655f

41. Thamilselvi V, Radha KV (2013) Synthesis of silver nanoparticles from Pseudomonas putida NCIM 2650 in silver nitrate supplemented growth medium and optimization using response surface methodology. Dig J Nanomater Biostructures 8:1101-1111

42. Shivananda CS, Asha S, Madhukumar R, Satish S, Narayana B, Byrappa K, Wang Y, Sangappa Y (2016) Biosynthesis of colloidal silver nanoparticles: their characterization and antibacterial activity. Biomed Phys Eng Express 2(3):35004. https://doi.org/10.1088/2057-1976/2/3/035004

43. Van Der Wal A, Norde W, Zehnder AJB, Lyklema J (1997) Determination of the total charge in the cell walls of Gram-positive bacteria. Colloids Surf B: Biointerfaces 9:81-100. https://doi.org/10.1016/S0927-7765(96)01340-9

44. Abbaszadegan M, Huber MS, Gerba CP, Pepper IL (1993) Detection of enteroviruses in groundwater with the polymerase chain reaction. Appl Environ Microbiol 59(5):1318-1324. https://doi.org/10.1128/aem.59.5.131 8-1324.1993

45. Seong M, Lee DG (2017) Silver nanoparticles against salmonella enterica serotype typhimurium: role of inner membrane dysfunction. Curr Microbiol 74(6):661-670. https://doi.org/10.1007/s00284-017-1235-9

46. Khalandi B, Asadi N, Milani M, Davaran S, Abadi A, Abasi E, Akbarzadeh A (2017) A review on potential role of silver nanoparticles and possible mechanisms of their actions on bacteria. Drug Res (Stuttg) 67(02):70-76. https://doi.org/10.1055/s-0042-113383

47. Quinteros MA, Cano Aristizábal V, Dalmasso PR, Paraje MG, Páez PL (2016) Oxidative stress generation of silver nanoparticles in three bacterial genera and its relationship with the antimicrobial activity. Toxicol Vitr 36:216-223. https://doi.org/10.1016/j.tiv.2016.08.007

48. Su HL, Chou CC, Hung DJ, Lin SH, Pao IC, Lin JH, Huang FL, Dong RX, Lin JJ (2009) The disruption of bacterial membrane integrity through ROS generation induced by nanohybrids of silver and clay. Biomaterials 30(30): 5979-5987. https://doi.org/10.1016/j.biomaterials.2009.07.030

49. Du J, Singh H, Yi T-H (2017) Biosynthesis of silver nanoparticles by Novosphingobium sp. THG-C3 and their antimicrobial potential. Artif Cells Nanomedicine Biotechnol 45(2):211-217. https://doi.org/10.1080/21691401.2 016.1178135

50. Kalishwaralal K, BarathManiKanth S, Pandian SRK, Deepak V, Gurunathan S (2010) Silver nanoparticles impede the biofilm formation by Pseudomonas aeruginosa and Staphylococcus epidermidis. Colloids Surf B: Biointerfaces 79(2):340-344. https://doi.org/10.1016/j.colsurfb.2010.04.014

\section{Publisher's Note}

Springer Nature remains neutral with regard to jurisdictional claims in published maps and institutional affiliations.

\section{Submit your manuscript to a SpringerOpen ${ }^{\circ}$ journal and benefit from:}

- Convenient online submission

- Rigorous peer review

- Open access: articles freely available online

- High visibility within the field

- Retaining the copyright to your article

Submit your next manuscript at $\boldsymbol{\nabla}$ springeropen.com 